\title{
Article
}

\section{Successful Collaboration in Social Care}

Practice: Beneficial Success Points of Interest for the Young Person in Swedish Juvenile Care

by

Goran Basic

Associate Professor in Sociology

Faculty of Social Sciences

Department of Pedagogy and Learning

Linnaeus University

35195 Växjö, Sweden

goran.basic@Inu.se

+46(0)470708959

Keywords:

inter-professional collaboration, child welfare system, social work practice, collaboration identity, field work, participation in the community

(c) (i) (2)

This work is licensed under a Creative Commons Attribution-ShareAlike 4.0 International License. 


\section{Abstract}

The aim of this ethnographic study is to analyse themes for 'the successful collaborations' that emerge from the study field notes on youth in Swedish juvenile care, and that can be interpreted as beneficial for these youth. These successful collaborations were observed, for instance, at meetings where the young persons were being discussed, and where an observer could distinguish planning for them that was carried out practically. The empirical base for this study is its total of 119 field observations/notes. The examples analysed reference a completed appointment for an eye test, a practical realization of active leisure, homework help and an internship placement that works. The coherence of three actors belonging to three different categories (coherent triads), and success points of interest that benefit the youth in the situation, create the image of a positive development for them. In this way, common identities of interplay that are useful for the young person are created and elucidated. The physical presence of the young person in these situations is an especially important theme for the 'successful collaboration'. This study shows that trust and motivation are important aspects for a successful collaboration and inclusion of less powerful individuals and groups of individuals within a community. Young people discussed in this study receive confirmation of their identities by participating in the community, with a successful interaction between actors in juvenile care a prerequisite for successful involvement and integration.

\section{Keywords:}

inter-professional collaboration, child welfare system, social work practice, collaboration identity, field work, participation in the community

\section{Introduction}

The purpose of this ethnographic study of youth in Swedish juvenile care is to analyse themes of 'successful collaboration' as described in the study field notes, and that can be interpreted as beneficial for the youth in question. ${ }^{1}$ The study's research question is: In interpersonal interactions in juvenile care, how actualized is the successful collaboration beneficial for the young person in the context? Analytical findings are presented in the following themes for 'success points of interest': (1) completed appointment for an 'eye test', (2) practical realization of 'leisure activity', 
(3) homework help, and (4) internship placement that works (regarding the term 'success points of interest', see the section Theory: Interaction, dyads and triads).

In Sweden, more than half of all special youth homes are privately run (Swedish residential care), while the rest are operated by the municipalities, the National Board of Institutional Care (NBIC) or Statens institutionsstyrelse (known as SiS). The institutions operated by the NBIC differ from the rest because they are the only ones with far-reaching disciplinary powers. Thus, these institutions are special and considered a last resort in the Swedish system.

The project, 'Counteract Violence and Gangs', conducted in Sweden from 1 July 2006 to 31 December 2008 (MVG project) aimed to enhance the collaboration between social services and the Swedish NBIC, and to streamline actions for youths in social care and their families. With this initiative, a new position was established, namely that of a coordinator with two responsibilities: (1) coordinating officials' actions regarding youths in social care to ensure that officials meet their commitments; and (2) to some extent, functioning as a sort of extra, state-employed parent. One example of such a commitment for the coordinator is the arrangement of school and leisure activities after a stay in an institution (Basic, 2012-2018).

Three researchers (Basic, Thelander, \& Åkerström, 2009) collected the empirical material for this study during the MVG project. My previous analysis of this empirical material (Basic, 2012) showed that when a new collaborative project is being launched and organizations are brought closer, cooperation can become a struggle, so that neither inter-organizational nor interpersonal collaboration seems to be supportive for the client. Young persons who were involved in the MVG project took part in interactions with officials, who were expected to work together with the best interests of the youngsters and their parents at heart. These officials presented a negative image of their collaboration partners. The impact that this behaviour had on the treatment of the young persons is clarified by the result of the effect evaluation of the MVG project. Lundström et al. (2012, p. 64) concluded that the coordinators' efforts were not beneficial for youngsters participating in the project. By analysing both positive and negative empirical examples of collaboration, we can see what 
does and does not work, and discern the value of comparing and contrasting the reasons.

\section{Collaboration in previous research}

Collaboration is an important aspect of social care practice, with previous collaborative research showing that conflicts are common among collaborating actors, organizations and authorities that are supposed to cooperate (Gardner, 2015; Hesjedal, Hetland, \& Iversen, 2015; Sundqvist, Ögren, Padyab, \& Ghazinour, 2016; Wieczorek, Marent, Dorner, \& Dür, 2016).

Lindberg (2009) states that factors contributing to the success of collaboration include the following: Leadership and functional borders are decided in an appropriate manner, organizations are located at the same place, administrative and political management and finance are coordinated, cooperation includes all levels in the involved organization, mutual trust and respect exist between the cooperating parties, mutual additional training of all personnel is provided, mutually beneficial development projects are conducted and economical stimuli or forced legislation exist. Many of the factors listed above involve actors who should become 'the same type' (e.g. mutual education, mutual housing, etc.). The picture presented in the research above demonstrates that collaboration is a phenomenon that occurs between equal rather than unequal actors.

However, these publications above are not enough to support the hypothesis that a collaboration will necessarily improve a client's situation or reduce work overlap. A structural unwillingness to collaborate with other organizations exists and is notable in human care, in which the client is outside of the organization's control.

Researchers have highlighted the importance of field notes and observations, but have not focussed on the analysis of field notes and observations about successful cooperation in short-term interactions between professionals and within this particular context (Blumer, 1969/1986; Emerson, Fretz, \& Shaw, 1995; Hammersley \& Atkinson, 1991/1983). 


\section{Theory: Interaction, dyads and triads}

This study's general analytical starting point is interactional, but is influenced by an ethno-methodological perspective on how people describe their social reality (Blumer, 1969/1986; Garfinkel, 2002). Collins (2004) claims that social life is shaped by a series of rituals, in which individuals are linked together by a common point of interest drawing their attention. When individuals move between different situations, they cannot disregard their experiences from earlier situations; former situations are intertwined with new ones, Collins points out. Collins calls these repeated interactions, in which individuals show respect and reverence for charged symbols ('sacred symbols'), 'interaction rituals' (2004, pp. 58-59, 109).

Interaction and the understanding of social reality affect relationships of different kinds; they construct and reconstruct both a dyad, involving actors within couple relationships, and a triad, a relationship among three actors. In addition to this general starting point, the concepts of 'dyad' and 'triad' are relevant themes in observations I have analysed (Simmel, 1950/1964).

Simmel (1950/1964) understood social interaction as a relationship, a type of interpersonal interaction that can indicate and adopt different social forms. For example, conflicts and relationships between and among members in dyads and triads are characterized by particular forms of interaction that become visible in the analysis of relationships between individuals and groups. Dyadic relationships are characterized by an intimacy between two parties, duties and responsibilities in relation to each other, and an intensity in the relationship. This constellation is very vulnerable, intense and volatile, and frequently causes conflict (Simmel, 1950/1964, pp. 122-125).

The entrance of a third party into a dyadic relationship can create space for other forms of interaction. According to Simmel, three individuals or three groups of individuals (and as many possible relationships among these groups) result in a situation in which one actor in the triad ends up outside of the context; i.e., an alliance between two members can be created as an antipole to the third member (Simmel, 1950/1964, pp. 135-136, 145-169). According to Simmel, relationships in a triad are unstable and easily changeable, and constellations of alliance can shift 
during the interaction. The creation of alliances commonly emerges in combat situations, and actors within these combat situations act strategically.

Simmel (1950/1964) argues that conflicts are conditional to relationships, and that conflicts in interpersonal interactions are an expression of unity with an integrating function between actors. Unity is created in exchanges between conflict and agreement, and between disputation and the quest for harmony and peace. Fighting parties can focus on a point of interest during conflicts, but points of interest within a single conflict may also shift.

What does Simmel write about consensus in triads? We can name two dimensions that partly answer the question. The first dimension is conflict-of-interest points, whose existence enables a dispute between arguing actors in the same way that a loss or lack of focus regarding a disputed item reduces conflict. A wide range of conflict-of-interest points within the context of youth care in Sweden is discovered in empirical material and analysed in Basic (2012). Possible conflicts of interest include, but are not limited to, which documents and concepts are used; which actor adopts which role(s); conflicts of communication; abuse of or by institutions; and disagreements regarding the work methods of an individual actor or group, planning for a young person and placement. Loss of conflict-of-interest points may create a 'triad stillness' among the involved actors (Basic, 2012, pp. 113-114, 129).

The second dimension has its attachment in the third actor's behaviour in the triad. Simmel (1950/1964, pp. 145-169) observes multiple all-embracing strategies that the third actor can imagine using in the interaction. One such strategy is to mediate while adopting a non-partisan position (the Non-Partisan and the Mediator). In this strategy, as a non-partisan mediator, the actor tries through verbal contributions to subdue conflicts that have existed in previous interactions. The appearance of these actors and the loss or lack of focus on conflict-of-interest points characterizes the collaboration in the triad between different categories, and thus the 'successful cooperation' that can be seen in the study's empirical material. Some examples of actors that belong to different categories, and also appear unanimous in the triad, are presented in the analysis. This situation can involve different constellations, such as young person/contact person at an institution/social secretary, young 
person/psychologist at an institution/contact person at a social service, young person/mother/home therapist or young person/principal/coordinator.

Success points of interest in the interaction are permeated by the 'right morality' in the situation. Everyone present in this study seems to agree about the importance of a completed appointment for an 'eye test', a practical realization of 'leisure activity', homework help and an internship placement that works for the young person. A fruitful participation in interaction rituals creates and re-creates the morality as well as the belonging among actors, and contributes to the appearance of other points of interest that in turn are used in the coming rituals (Collins, 2004). Morality emerges in the interaction between people, and especially in the meeting with groups that digress from the morality that a member perceives as 'right'. The morality that permeates the above sequence is acted out by real persons, and is a product of a dynamic process. The morality in the situation can be redefined, changed, produced anew and reconstructed during one occasion of interaction, or during what Collins (2004) calls an interaction chain.

\section{Method: Ethnography and variation in the empirical material}

The study was conducted based on inspiration from ethnographic tradition (Hammersley \& Atkinson, 1991/1983). The empirical base for this study is its total of 119 field observations/notes. The observations took place at meetings where the young persons were being discussed, and where an observer could distinguish planning for them that was carried out practically, both before and after these meetings and during visits to youth care institutions in Sweden, social services offices and the Swedish NBIC. This article is based on an analysis of seven empirical sequences from these field notes. This empirical example is part of six transcribed and rendered field observations from six organized meetings with professional actors and four young persons in Swedish juvenile care. The fictional names of these young persons in the following analysis are Nesim, Elsa, Priscilla and James.

Emerson, Fretz, and Shaw (1995, pp. 2-16) argue that for some research purposes, it is best to observe situations when they actually occur, which allows the researcher to collect empirical material in a natural environment and in real situations. An important point is that a detailed description of social life is one of the foundations of 
ethnographic knowledge gatherings. Some of the field notes in this study have been collected through so-called 'go-alongs', with the aim of producing more grounded knowledge by researchers who are following those they are studying in daily life (Kusenbach, 2003). The coordinators were particularly followed with the ambition to somehow 'capture' their work. The method was to interview these coordinators at the beginning and end of the project, and to conduct field observations of their practical work and field interviews during the field work. The observations could be about observing the coordinators' discussions and internal meetings, phone calls with actors within the youth welfare, the coordinators' practical encounters with both youngsters and parents and with the institution staff and social workers.

In this study, the researchers sought to write down as much information as possible, with a few focus points on the coordinators, the project and other actors in the youth welfare. Field notes were written down while the interviews were being conducted, during organized meetings within the project, through dialogs conducted during travels, before and after interviews and during visits at social services offices and institutions. Furthermore, notes were written down during observations of the coordinators' work with six youngsters in meetings at special childcare units and social services offices where these youngsters attended and were discussed. The researchers in the study sought to create the variety in the empirical material required to differentiate, and in the next stage analyse a successful collaboration beneficial for a young person in this specific context.

Themes for the successful collaboration in social work practice described in the study's field notes are analysed here. Concurrence in interaction takes place here, in connection with organized meetings. 'Concurrence' indicates themes in the material in which actors appear or are described as appearing as unanimous in the triad; that is, as three unanimous actors who belong to three different categories (Simmel, 1950/1964). The above approach provided good opportunities to comment on and document the details of the printed material in the empirical analysis. Reading and commenting on the printed material allowed for completion of a categorization of empirical material (see 'data analysis' in Silverman, 2015; and 'thematic analysis' in Guest, MacQueen, \& Namey, 2012). 
Empirical sequences presented in this study were categorized in the material as 'success points of interest: eye test', 'success points of interest: leisure activity', 'success points of interest: homework help' and 'success points of interest: internship placement'. The coding statements and notes allowed the identification of themes for successful cooperation in the material. The choice of empirical examples was based on the study's purpose (to analyse themes of 'successful collaboration' as described in the field notes of the study, which can be interpreted as beneficial for the youth in question) and the ability of the examples to elucidate the analytical points.

In the following analysis, I designate as success points of interest (Simmel, 1950/1964; Collins, 2004) a completed appointment for an 'eye test', the practical realization of a 'leisure activity', homework help and an internship placement that works, all of which are beneficial for the young person. These examples of 'successful collaboration' could be perceived as banal and 'too ordinary' by the professional actors in the so-called youth care, but the reason I chose to present and analyse these successful cases is the absence of examples of 'the successful collaboration' in my empirical material, where all three categories are coherent and where the different specific occupational competencies of the officials are more salient. I also claim (as do many other researchers and attentive practitioners) that successes related to eye tests, active leisure, homework help and internship placement are not necessarily banal. An eye test is important for an individual's health (and academic success if an individual needs glasses) and both active leisure and internship and school placement that work to lessen the risk of becoming involved in criminality (Hirschi, 1969).

\section{Success points of interest: Completed appointment for an 'eye test'}

In this study, 'the successful collaboration' is analysed only in those cases involving three actors from three different categories who are content in the situation. Common identities of collaboration seem to be important for 'the successful collaboration', and these are created and re-created in the interaction. In the empirical material for this study, coherent triads and success points of interest beneficial for the young person can be distinguished. The physical presence of the young persons in these situations is of special importance. 
This analytical reasoning can be exemplified by the examples below. In one meeting, the opinion of a youth about his treatment is being commented on when the contact person at the institution says that the youngster has to express his opinion 'in a reasonable way'. The contact person also says that 'we have to practise on this'. During the meeting, it is revealed that Nesim (as noted, all names of persons have been changed, as have the place names) is going to take part in an ART (Aggression Replacement Training) group, and that this will be that type of practice. The contact person goes on to say that Nesim's eyesight needs to be investigated. At the next meeting, the ART course experience is being followed up and commented on. The contact person says:

'Nesim is partaking heart and soul in these activities here at the institution and it's working out fine'. The contact person says that the youngster is in an ART group and that he thinks it is fun. 'Especially the role-play, don't you, Nesim?' Nesim smiles and nods. The contact person: 'Nesim is important in the ART group, he has set the standards for the others.' (field notes)

In the empirical material for this study, there are examples in which the youngster is rewarded, and progress in school or other activities is discussed. The conduct of the youth is said to have improved, and the health situation is also discussed. The field notes can be interpreted as a description of daily life at the institution that is created and re-created in the myriad of everyday interactions. Through a series of typifications, the contact person seems to create a common identity with the youth, a strong 'we' or an alliance (Blumer, 1969/1986; Gardner, 2015; Simmel, 1950/1964; Wieczorek et al., 2016). But these and similar examples cannot be analysed as a representation of a successful collaboration according to the premises of this study. $A$ successful collaboration only exists if there are three actors belonging to three different categories who are content with the situation (Basic, 2018a, 2018b, 2015b). During the same meeting, the eye test is being commented on when the social secretary says that they will go through the plan of implementation:

The first issue is health, it is being said that an appointment with the dentist is going to be made. The eye test that was mentioned at the former meeting is done and led apparently to a couple of pairs of glasses /.../ Later on, exercise was spoken of; Nesim is, according to the contact person, not interested in any particular kind of sport, but he has walked some long rounds of exercise during the time at the institution and takes part in the common exercise activities. Here, Nesim gets credit by somebody (the social secretary or director of the department) for having lost weight. Regarding other leisure activities, it says in the plan of implementation that the institution will try to find some kind of 'special interest' for Nesim, but that has not yet been found. The contact person 
says that they will have to ponder a bit more on this, and Nesim nods and agrees. The social secretary continues: 'And school is working well?' (field notes)

In the sequence above, a completed eye test and common activities at the institution (partaking in the ART course and the exercise activities) are being highlighted. These make visible the picture of a coherent triad constituted by young person, a contact person at an institution and the social secretary. In this interaction, a success point of interest is being constructed, consisting of Nesim's participation and the successful accomplishment of the eye test.

According to Simmel (1950/1964), struggles are suppressed at the falling-off, or the absence of points of conflicts of interest. In the field notes above, the struggles are muted and not visible. The members of the meeting seem to be pleased with the situation, particularly Nesim, who 'smiles and nods'. The benefit for the youth that can be gathered by the situation above is based on the presence of the youth in the situation. In Basic (2012, pp. 116-117), attention is drawn to the fact that the presence of the youth and parents during the meetings in special youth care homes is not always guaranteed. If we follow the reasoning of researchers about the importance of the participation of the youth and parents for a successful cooperation, we can conclude that the presence of the youth is especially important in the observed scenario (Gardner, 2015; Wieczorek et al., 2016).

The observed situation above can be interpreted as the praxis-grounding, selfevident and (un)spoken web of interaction and unity that seem to constitute the relationship among the members of the meeting. The actors in the context are represented as taking part in a unity that consists of the coherent triad. The harmonized triad performance of the actors and rhetoric shape the picture of the coherent triad. No threat to the unanimous triad is visible, and no rhetoric used could exclude anyone (Basic, 2018a, 2018b, 2015b). The presented performances during the meeting also offer insight into the balanced morality value of the unity (Gardner, 2015; Hesjedal et al., 2015; Sundqvist et al., 2016; Wieczorek et al., 2016). The actors' resources in the form of rhetoric act as a stimulant for the other members to embrace the speaker's definition of the 'self' and 'others'. In this case, the morality balancing becomes an instrument to establish and uphold positions in the situation. 


\section{Success points of interest: Practical realization of 'leisure activity'}

The production of a successful collaboration depends on the actors' social and moral production, in which the rhetoric is essential. The actors strive to portray themselves as competent, and the concurrence in the triad seems to maintain a certain normative and moral order in the situation.

The construction of success points of interest for cooperation is an ongoing, narrative and interactive process. Success points and the proper morality that are created and recreated during interactions cannot be found in an essential and consistent form, but instead emerge through the interaction of the actors. In that process, the image of a beneficial position for the youth in question can be distinguished.

The next sequences are about a contact person who has assisted at the concretization of an 'active leisure' for a young person. This contact person has been engaged by a request from a psychologist at the institution. In an extract from two observations, we can see how this request takes shape in a follow-up after a placement at an institution. During the meeting at the department of commission, the observer writes:

The psychologist (at the department of commission) regards the support of the mother and the stepfather as important, and also a help for an active leisure for Elsa. (field notes)

After a few weeks, a follow-up meeting is held at the social service office:

The mother comes now, too, and says that Elsa is with the contact person doing a workout (gym, strength and fitness, if I understand it correctly). So Elsa is a bit late for the meeting; they thought it's important to get the workout started, explains the mother. (field notes)

In the sequence above, an important success point of interest-the accomplishment of 'active leisure'-is presented. In this harmonized interaction, there is a coherent triad among a psychologist at an institution, a contact person at a social service office and a young person. This situation gives the image of a young person who has won approval in the situation, thereby achieving a beneficial position.

The morality of the actors appears in different interactive patterns in this study. It seems that the morality is part of the construction of a successful collaboration 
(Gardner, 2015; Hesjedal et al., 2015; Sundqvist et al., 2016; Wieczorek et al., 2016). The appearance of the actors seems to be affected by their ambition to present themselves as capable, and in those appearances, the actors tend to uphold a certain normative and moral order in the situation. In that way, the construction of the successful collaboration also becomes dependent on the actors' social and moral production, in which rhetoric is frequently used.

\section{Success points of interest: Homework help}

The successful collaboration seems to be supported if the actors complete each other in the interaction and construct mutual success points of interest. In that way, common interplay identities, beneficial for the young, can be created and made visible.

When authority personnel attempt to be included in a coherent triad with the external actor (parents or youngsters) during a meeting, that attempt can be interpreted as an effort to ease the atmosphere by creating distance from their professional coworkers. By distancing, the conflict-of-interest points that were actualized in previous interactions are erased (Simmel, 1950/1964). It seems that a successful cooperation can produce and reproduce a new concurrence in relationships between authority personnel and actors who are outside organizations, i.e., youngsters and parents.

The girl Priscilla has returned home after her stay at an institution called Blendius. Participating in the first meeting at the social services office in the municipality of residence are Priscilla, Priscilla's mother Mina, home therapist Britt-Marie, social secretary Rose-Marie and the coordinator. During the meeting, Rose-Marie explains that the home therapist should be helping with Priscilla's homework, in addition to ensuring that it is completed:

Britt-Marie shall be a support with the planning at home when it comes to ordinary chores such as buying groceries, laundry, and also help with the planning of the economy so that it's stable. Mina (mother) looks sceptical, RoseMarie clarifies: 'Because I've gotten reports that it's not always functioning at home, that Priscilla, for example, stayed home because she had no clean clothes, and she once said that she hadn't eaten because there was no food, and therefore had been tired in school.' The mother gets very upset now: 'I am doing all possible to make sure I manage my home and the kids. You only look 
backward, only see problems. But you said that now, here at Blendius, we were going to look ahead. So, this is extremely hard for me!' /.../ The tears are near, and Mina rapidly rises up and leaves the room, the youngster follows. 'I'll go with them', says Britt-Marie, and goes after them. /.../ After a couple of minutes, the youngster and the mother return, followed by Britt-Marie. (field notes)

In the situation above, a coherent triad can be inferred from the relationships among the home therapist, the mother and the youngster. In this situation, the coordinator and social secretary are excluded. The exclusion of the coordinator and the social secretary described above seems to have originated in social secretary Rose-Marie's accusing tone directed to the mother Mina ('I've gotten reports that it's not always functioning at home'). The defence against the attack appears to form a coherent triad, including Mina, Priscilla and the home therapist, against the social secretary Rose-Marie and the coordinator.

The shared exit and entry of the home therapist Britt-Marie, mother Mina and daughter Priscilla at the meeting projects the image of a concurrence that excludes the actors sitting down in the office, i.e., social secretary Rose-Marie and the coordinator (and the observer). By walking in the office together with the mother and daughter, Britt-Marie appears to escort Mina and Priscilla, which can be interpreted as a display of unity and coherence in the triad (formation of coherent triad against the coordinator and social secretary).

Home therapist Britt-Marie's attempt to be a part of a coherent triad with the mother Mina and Priscilla can also be seen as an attempt to ease the atmosphere during the meeting. One way to calm the external actor is to distance oneself from one's superiors (Caplow, 1968). Simmel (1950/1964) argues that the loss or absence of focus on the conflict-of-interest points diminishes battles. By distancing herself from her superior, home therapist Britt-Marie erases conflict-of-interest points that were actualized by the statement, 'Priscilla /.../ had no clean clothes, and she once said that she hadn't eaten because there was no food.' When Britt-Marie leaves the meeting with Mina and Priscilla, she creates distance from the other members at the meeting and therefore from social secretary Rose-Marie, who in this context is the only actor who has a decision-making mandate, and is also the person who hired Britt-Marie. 
The special thing with Mina and Priscilla is that they are not members of any organization. Yet, the authority personnel seem to seek concurrence in the triad with Mina and Priscilla. When Mina and daughter Priscilla leave the meeting, home therapist Britt-Marie follows.

Triad constellations, in which actors are outside organizations, have been studied before. What is especially interesting is that interpersonal alliance constellations may shift during 'interaction heat'. Interpersonal alliances can shift during a situation regarding interaction, and every interaction may contain more alliances that differ in themes, durability and the actors' goals (Gardner, 2015; Hesjedal et al., 2015; Sundqvist et al., 2016; Wieczorek et al., 2016). Researchers acknowledge that 'temporary alliances' may shift during the interaction, and that these most often become 'short lived'. Caplow (1968), who has studied relations between organization representatives and actors who stand outside organizations, argues that an alliance may form in combat situations, and that combat actors may act strategically. In my study, youngsters and parents are sometimes involved in these situations, so a concurrence in the triad between authority personnel and actors outside the organization may emerge. We have the mother Mina and the daughter Priscilla in the field notes above, together with the home therapist Britt-Marie, who seems to seek to make herself part of a coherent triad with Mina and Priscilla ('I'll go with them', said Britt-Marie and goes after them'”). Caplow (1968, p. 136) writes the following about cross-border alliances:

In some other types of organization, triads involving outsiders are much more conspicuous and important. These may be called boundary triads. From one point of view, the sine qua non of an organization-its fundamental and essential characteristic-is that any two of its members interacting with an outsider in the performance of their organizational roles tend to form an automatic coalition of us against you-and-your-associates.

Cross-border alliances are common within different service professions, in which cooperation among actors is encouraged because it is beneficial for the activity (Caplow, 1968, pp. 136-142). One overall image of the material for this study demonstrates that authority personnel in the youth care system usually experience cross-border alliances with youngsters and parents, including some that are beneficial to- and some that are obstacles for the treatment. It is a common strategy for clients in human service organizations to try to enter into alliances with 
professionals involved in their cases and, in so doing, attempt to alter the situation to their own advantage (Basic, 2012). The client often seeks these alliances, which indicates the client's will to fight against the situation that they are in, which can be seen as something productive rather than problematic.

\section{Success points of interest: Internship placement that works}

The success point of interest-an internship placement that works-emerges in the empirical material for this study as a rhetorical tool to bring attention to a young person's success. That James (the young person in Swedish juvenile care) 'is in a dog care centre and likes it well enough' can be seen as an interactive receipt, proof of 'the successful collaboration' in the coherent triad among young person, principal and coordinator. The youngster, headmaster and coordinator seem to complete each other during the interaction.

In the following sequences, the planning for the youth after his stay at an institution is discussed. In this case, the planning, division of labour and follow-up regarding an internship placement seem to work out smoothly, and illustrate 'the successful cooperation'. During the meeting at the institution, one discusses the adjusted schooling before discharge:

The mother and James think that their relation and communication have improved, something they think is due to the fact that James is now free of drugs. /.../There is a discussion about what the school can offer, it is about a combination of theory and practice where James is supposed to be in school mainly on Thursdays and Fridays. The headmaster: 'We could also offer something on Mondays and Wednesdays; we can discuss about that. It could be a support in other subjects or some kind of practice'. The coordinator: 'What do you think about that, James, if you were to not have Mondays and Wednesdays in school?' James: 'I need routines, need to get up in the morning'. 'Yes, but we can arrange a practice for you, we can solve that', says the headmaster. (field notes)

After some weeks, the practice is being discussed during a meeting at the social service office:

First, James tells about his practice. He is in a dog care centre and likes it well enough. It's about taking the dogs out, feeding them, etc. (Field notes)

Previous research shows that professional actors join a coherent triad with outstanding actors (parents or youths) to ease tension from previous conflicts (Gardner, 2015; Hesjedal et al., 2015; Sundqvist et al., 2016; Wieczorek et al., 2016). 
Several studies have given descriptions of a clearer cooperation identity through a close collaboration (Gardner, 2015; Wieczorek et al., 2016). The construction of common success points of interest, as well as completion of each other's acting in the interaction, seem to encourage a successful collaboration, and can be beneficial for the young person in the situation.

In the above sequences, there are no defined barriers between professionals and youth and parents (Basic, 2018a, 2018b, 2015b). Researchers claim that crossborder alliances between the professionals, youth and parents are cardinal aspects for a successful cooperation (Gardner, 2015; Wieczorek et al., 2016). Inclusion of the parents in the collaboration in an active and participatory way contributes to rebuilding their parenthood. The roles of James and his mother in the human care organization seem to produce and reproduce new coherences in relations, but this process assumes an organization that is flexible and can change its structure when necessary.

\section{Discussion}

This article presents an analysis of a successful dimension of the phenomenon of 'collaboration', which can be interpreted as beneficial for youth in the juvenile care context. Themes for 'the successful collaboration' described in the field notes of the study, and that can be interpreted as beneficial for the youth in question, are analysed. The examples being analysed are about a completed appointment for an eye test, a practical realization of active leisure, homework help and an internship placement that works. In these empirical examples, a coherence of three actors belonging to three different categories can be distinguished.

Coherent triads and success points of interest beneficial for the youth in question also constitute the image of a positive development for the youth. The successful collaboration seems to be fostered if the actors complete each other in the interaction and construct common success points of interest, as with a completed eye test, a practical completion of an 'active leisure', homework help and an internship placement that works. In that way, common identities of interplay are also created and made visible, yielding benefits for young people. That the young are physically present is highly important for 'the successful collaboration', and to create and re- 
create coherent cross-border triads consisting of public officials in youth care and young person and parents.

The organizational agreements of cooperation and official meetings are not vital to collaboration - such practices are not the key to successful cooperation. Partners need to literally and figuratively understand each other, in addition to each other's working methods, aims, goals and motivations (or lack of motivation). Participating in meetings with other professionals stimulates successful cooperation, but problems arise when actors outside the organization are present (e.g. in this study, parents or youths).

An analysis of the empirical material in this study shows that professional actors join a coherent triad with outstanding actors (parents or youths) to ease tensions from previous conflicts. Creating distance from their professional partners erases the conflict-of-interest points actualized earlier. The typical process is that the professional actors, through their verbal additions, mitigate the conflicts present in the earlier interactions. The prominence of these actors, and a loss or lack of focus on the conflict-of-interest points, characterizes the consistency of the triad among different categories, and thus a successful cooperation.

Alliances between organization representatives and actors who stand outside the organization, or so-called cross-border alliances, are common in service occupations where cooperation between actors is sought because it is seen as beneficial for the activity. This study shows that the formation of larger alliances/triads across organizational boundaries can ensure a successful cooperation.

Between organizational interactions, identities are created and re-created in parallel with the professionals' identity work. It seems that the professionals' professional identities are constructed and reconstructed, both by interaction with the others and through a distinction of the other by exclusion of that party. Success points of interests and the proper morality created and re-created during interactions appear in the myriad everyday interactions, constructed through conflict, joint effort and everyday routines. Social interactions produce a greater sense of trust and motivation, hence resulting in organizational productivity. Trust between collaborating 
partners increases participants' risk-taking, because they know what to expect from their partners and how collaborating organizations work.

An interesting issue that has arisen during working with the material for this study is if - and if so, how - the different categories analysed bring attention to leadership for the successful collaboration. What significance do one or many competent leaders have for the successful cooperation? Should the supervisors be the ones who stimulate their employees to cooperate cross-border? Are the supervisors supposed to ensure sufficient time to cooperate? In this respect, previous research shows that cooperation sometimes takes a considerable amount of time, at the cost of working with clients.

Another interesting question regarding the phenomenon of 'cooperation' that could be investigated is who is responsible for the successful cooperation. A situation, in which the expectations are that actors $A, B$, and $C$ will cooperate and achieve a satisfactory goal for the client, requires one or several responsible actors. Is one actor supposed to be responsible for every actor's satisfaction and ensure a beneficial situation for the client? Or are several actors-or even all members of the situation-required to share the responsibility? Different scenarios seem to demand different strategies. Moreover, well-reasoned strategies are required to face territorial attitudes that do not support the formation of an in-group identity.

\section{Conclusion}

Social work is one of the perspectives in social sciences emphasizing the importance of trust and motivation for the successful collaboration and inclusion of less powerful individuals and groups of individuals within a community. The young people discussed in this study receive confirmation of their identities by participating in the community, with a successful interaction between actors in juvenile care a prerequisite for a successful involvement and integration. One of the key dimensions of future research in social work is to analyse the relationships between less powerful individuals and groups in need of help from various professional actors in a social work context, whose role in the course of their professional activities is to assist these individuals and groups. 


\section{End notes}

1. Some parts of this text were published earlier in Swedish in the book, 'Successful collaboration. Described and observed experiences of youth care' (Basic, 2015b), and in English in the articles, 'Coherent triads and successful inter-professional collaboration: Narratives of professional actors in Swedish child welfare system' (Basic, 2018a), and 'Observed successful collaboration in social work practice: Coherent triads in Swedish juvenile care' (Basic, 2018b). 


\section{References}

Basic, G. (2018a). Coherent triads and successful inter-professional collaboration: Narratives of professional actors in Swedish child welfare system. Nordic Social Work Research. https://doi.org/10.1080/2156857X.2018.1518817

Basic, G. (2018b). Observed successful collaboration in social work practice: Coherent triads in Swedish juvenile care. European Journal of Social Work, 21(2), 193-206. https://doi.org/10.1080/13691457.2017.1289897

Basic, G. (2015a). Ethnic monitoring and social control: Descriptions from juveniles in juvenile care institutions. Nordic Social Work Research 5(1), 20-34. https://doi.org/10.1080/2156857X.2014.920273

Basic, G. (2015b). Successful collaboration. Described and Observed Experiences of Youth Care. Malmö: Bokbox Förlag.

Basic, G. (2013). A case of what? Methodological lessons from a reanalysis of conflicts within Swedish Juvenile Care. Journal of Comparative Social Work, 8(2), 222-250. https://doi.org/10.31265/jcsw.v8i2.102

Basic, G. (2012). When collaboration becomes a struggle. A sociological analysis of a project in the Swedish juvenile care. Lund: Lund University.

Basic, G., Thelander, J., \& Åkerström, M. (Ed.) (2009). A ‘Treatment Chain’ for Young People or the Professionals? A Process Evaluation of the 'Counteract Violence and Gangs'- Project in Sweden. Stockholm: Swedish National Board of Institutional Care, Forskningsrapport 2009:5.

Blumer, H. (1969/1986). Symbolic Interactionism. Perspective and Method. Berkeley, Los Angeles, London: University of California Press.

Caplow, T. (1968). Two against one. Coalitions in triads. New Jersey: Prentice-Hall, Inc., Englewood Cliffs.

Collins, R. (2004). Interaction Ritual Chains. Princeton: University Press. https://doi.org/10.1515/9781400851744

Emerson, R. M.; Fretz, R. I., \& Shaw, L. L. (1995). Writing Ethnographic Fieldnotes. Chicago: The University of Chicago Press. https://doi.org/10.7208/chicago/9780226206851.001.0001

Gardner, D. B. (2015). Ten Lessons in Collaboration. The Online Journal of Issues in Nursing, 10(1), Manuscript 1, https://doi.org/10.3912/OJIN.Vol10No01Man01. Garfinkel, H. (2002). Ethnomethodology's Program. Working Out Durkheim's Aphorism. London: Rowman \& Littlefield. 
Guest, G.; MacQueen, K. M., \& Namey, E. E. (2012). Applied Thematic Analysis.

Thousand Oaks: SAGE. https://doi.org/10.4135/9781483384436

Hammersley, M., \& Atkinson, P. (1991/1983). Ethnography: Principles in Practice.

London, New York: Routledge.

Hesjedal, E., Hetland H., \& Iversen, A. C. (2015). Interprofessional collaboration:

Self-reported successful collaboration by teachers and social workers in

multidisciplinary teams. Child \& Family Social Work, 20(4), 437-445.

https://doi.org/10.1111/cfs.12093

Hirschi, T. (1969). Causes of delinquency. Berkeley: University of California Press.

Kusenbach, M. (2003). Street Phenomenology: The Go-Along as Ethnographic

Research Tool. Ethnography, 4(3), 455-485.

https://doi.org/10.1177/146613810343007

Lindberg, K. (2009). Collaboration. Malmö: Liber.

Lundström, T., Sallnäs, M., \& Andersson Vogel, M. (2012). Evaluation of an

enhanced care chain of care for young people at an SiS institution. Final report.

Stockholm.

Silverman, D. (2015). Interpreting Qualitative Data. Thousand Oaks: SAGE.

Simmel, G. (1950/1964). The Sociology of George Simmel. Translate, editor and introduced by Kurt H. Wolff. New York: Glencoe Press.

Sundqvist, J., Ögren, K., Padyab, M., \& Ghazinour, M. (2016). Collaboration patterns among Swedish professionals in the repatriation of unaccompanied asylumseeking refugee children: An explorative study. European Journal of Social Work, 19(6), 901-916. https://doi.org/10.1080/13691457.2015.1082981

Wieczorek, C. C., Marent, B., Dorner, T. E., \& Dür, W. (2016). The Struggle for Inter-

Professional Teamwork and Collaboration in Maternity Care: Austrian Health

Professionals' Perspectives on the Implementation of the Baby-Friendly

Hospital Initiative. BMC Health Services Research, 16(91), 1-15,

https://doi.org/10.1186/s12913-016-1336-3 